\title{
Loss of PIG3 increases HIF-1a level by promoting protein synthesis via mTOR pathway in renal cell carcinoma cells
}

\author{
Guang Chen ${ }^{1,2, *}$, Jin-Ye $X u^{3,4, *}$, Jie Chen ${ }^{5}$, Jian-Xin Zhang ${ }^{5}$, Jun Zhou ${ }^{5}$, Yong Liang ${ }^{4,5}$ \\ and Xiao-Fei Ding ${ }^{5}$ \\ ${ }^{1}$ School of Pharmaceutical and Chemical Engineering, Taizhou University, Taizhou, Zhejiang, China \\ 2 Institute of Tumor, Taizhou University, Taizhou, Zhejiang, China \\ ${ }^{3}$ Laboratory of Cancer Biology, Provincial Key Lab of Biotherapy in Zhejiang, Sir Runrun Shaw Hospital, Medical School of \\ Zhejiang University, Hangzhou, China \\ ${ }^{4}$ Taizhou Municipal Hospital, Taizhou, Zhejiang, China \\ ${ }^{5}$ School of Medicine, Taizhou University, Taizhou, Zhejiang, China \\ * These authors have contributted equally to this work
}

Correspondence to: Xiao-Fei Ding, email: dxfei@tzc.edu.cn

Keywords: PIG3, HIF-1a, mTOR, renal cell carcinoma, migration

Received: August 24, $2015 \quad$ Accepted: March 16, 2016

Published: March 27, 2016

\section{ABSTRACT}

PIG3 is a target of the tumor suppressor p53 and is thought to be involved in p53-mediated cell apoptosis. Although PIG3 is similar to oxidoreductases involved in generating ROS, whether PIG3 would regulate HIF-1a was never characterized directly. Here we demonstrated that knockdown of PIG3 by transfecting with specific siRNA could increase the expression of HIF-1a in several human cancer cell lines, including CAKI, FTC-133 and A549. It indicates that PIG3 may be involved in the regulation of HIF-1a. Furthermore, we revealed that PIG3-siliencing increased HIF1a protein level through promoting its protein biosynthesis via mTOR pathway. In addition, the effect of PIG3 on the production of HIF-1a was further related to VEGF secretion and cell migration. PIG3-downregulation increased the secretion of VEGF and promoted the migration of renal cancer cells obviously. Taken together, these data suggest that PIG3 was involved in HIF-1a regulation, and reveal a novel signaling pathway of PIG3/HIF-1a in the regulation of cell migration in renal cell carcinoma.

\section{INTRODUCTION}

Hypoxia-inducible factor- $1 \alpha$ (HIF- $1 \alpha)$ is a major transcription factor responsible for the induction of hypoxia-response elements (HREs)-containing genes that facilitate adaptation and survival of cells and the whole organism under hypoxia [1]. To date, there are more than 100 hypoxia-inducible genes identified with varying functions, including those involved in erythropoiesis/ iron metabolism, angiogenesis, glucose, metabolism, cell proliferation/survival and apoptosis [2,3]. Overexpression of HIF- $1 \alpha$ was found in various human cancers, HIF- $1 \alpha$ downstream genes have been identified that are widely involved in the malignant features of tumors, including angiogenesis, invasion, metastasis, and drug resistance [4-6].

HIF- $1 \alpha$ is regulated in both oxygen-dependent and oxygen-independent manner. The ubiquitination-mediated degradation is the most important regulator of HIF-1 $\alpha$ levels. In normoxia, hydroxylation of two proline residues and acetylation of a lysine residue in its oxygen-dependent degradation domain (ODDD) promote the association of HIF-1 $\alpha$ with the von Hippel-Lindau (pVHL) ubiquitin E3 ligase complex, leading to HIF-1 $\alpha$ degradation via ubiquitin-proteasome pathway [7-9]. Besides pVHL, p53, HSP90, cJun, etcetera, have also been found to relate to HIF-1a ubiquitination and stability [10]. In addition, the mitogen-activated protein kinase (MAPK) pathway and PI3K/AKT/mTOR pathway seem to play important role in HIF-1 $\alpha$ expression [11-13]. Here, we found that knockdown of PIG3 mediated by siRNA transfection increased HIF-1 $\alpha$ protein level.

PIG3 (p53 inducible gene 3), also called TP53I3 (tumor protein p53-inducible protein 3), is one of the P53 
protein target originally indentified by Polyak et al [14]. To date, PIG3 has been found to participate in apoptosis, the generation of ROS, DNA damage response and mediating cancer cell death [15-17]. It is well known that PIG3 is a target of p53, but the down-stream signaling pathway of PIG3 is poorly understood.

In the present study, we showed that PIG3 may be involved in HIF-1 $\alpha$ regulation. And PIG3 knockdown mediated by RNAi could up-regulate VEGF secretion via HIF-1 $\alpha$ to promote renal cancer cell migration, which contributes to improve our knowledge of PIG3 function and $\mathrm{HIF}-1 \alpha$ regulation.

\section{RESULTS}

\section{PIG3 regulates cellular HIF-1 $\alpha$ protein level}

We first investigated whether PIG3 regulated HIF-1 $\alpha$ expression in human renal cell carcinoma cell. Knockdown the PIG3 expression by transfecting pig3specific siRNA in CAK-I cells, then the PIG3-silencing cells were exposed to $\mathrm{CoCl}_{2}$-induced hypoxia-mimic system for 6 hours to detect the HIF-1 $\alpha$ protein. As shown in Figure 1A, the protein levels of cellular HIF-1 $\alpha$ were obviously higher than those in the hypoxic negative control cells. Similar results were found in other cell lines, such as follicular thyroid cancer FTC-133 cells and nonsmall-cell lung cancer A-549 cells.

Moreover, the similar profiles were showed by transfecting two different siRNAs targeting PIG3 into CAKI cell (Figure 1B) and the same story was found in hypoxic condition under $1 \% \mathrm{O}_{2}$ (Figure 1C).

Furthermore, re-expression of PIG3 in siRNA experiment was done to rescue the phenotype of HIF-1 $\alpha$ increase, avoiding off target-effects. We conducted PIG3 complementation experiments by transfecting a plasmid carrying a point mutant PIG3 sequence (Figure 1D) into the PIG3-silenced CAKI cells. This plasmid expresses same protein, but its transcripts could not be disrupted by PIG3-siRNA due to their unpairing (Figure 1D). PIG3 complementation effectively blocked the increase of HIF-1 $\alpha$ protein levels induced by PIG3 loss (Figure 1D), indicating that PIG3 plays a causal role in the control of cellular HIF-1a protein levels.

\section{Knockdown of PIG3 Up-regulates HIF-1 $\alpha$ level through promoting protein biosynthesis}

HIF- $1 \alpha$ is regulated by various pathways at different levels [18]. Firstly, we detected the levels of HIF-1 $\alpha$ mRNA in the PIG3-knockdown CAKI cells to examine whether PIG3 affects the transcription of HIF$1 \alpha$. However, PIG3 silencing did not change the level of HIF-1 $\alpha$ mRNA, indicating that PIG3 does not affect the transcription of the HIF-1 $\alpha$ gene (Figure 2A).

Secondly, we investigated the alteration kinetics of the HIF-1 $\alpha$ protein levels in CAKI cells transfected with negative control or PIG3 siRNA responding to hypoxia. As shown in Figure 2B, in PIG3-knockdown CAKI cells, the levels of HIF-1 $\alpha$ protein went up earlier than those in the control cells on exposure to hypoxia. HIF-1 $\alpha$ protein levels increased significantly at the 2-hour time point in PIG3-silencing cells. In contrast, in the control cells, at the same 2-hour time point, the levels of HIF-1 $\alpha$ protein was much lower (Figure 2B). The result suggests that the loss of PIG3 is likely to promote the production of the $\mathrm{HIF}-1 \alpha$ protein.

To further examine whether the induction of HIF$1 \alpha$ protein in PIG3-knockdown cells is associated with its degradation, we exposed the cells to the protein biosynthesis inhibitor cycloheximide (CHX). The HIF$1 \alpha$ protein levels changed in the similar pattern in both cell (Figure 2C). The data indicate that PIG3 loss did not inhibit the protein degradation of HIF-1 $\alpha$.

\section{PIG3-siliencing promotes the production of HIF- 1a via PI3K/mTOR pathway}

It well known that PI3K/Akt/mTOR signaling pathway mediates HIF-1 $\alpha$ translation in various cancer cells $[11,12,19,20]$. We examined whether compounds targeting $\mathrm{PI} 3 \mathrm{~K} / \mathrm{mTOR}$ pathway would attenuate the production of HIF-1 $\alpha$ protein induced by PIG3-knockdown. As shown in Figure 3A, treatment of rapamycin at $10 \mathrm{nM}$ for $24 \mathrm{~h}$ or wortmannin $100 \mathrm{nM}$ for 8 h significantly inhibited PIG3-silencing-stimulated HIF-1 $\alpha$ going up in CAKI cells.

To further determine the role of mTOR in PIG3loss-induced HIF-1 $\alpha$ expression, we examined upregulation of HIF-1 $\alpha$ protein level induced by PIG3 loss after down-regulation of Raptor by transiently transfection of siRNA. As shown in the Figure 3B, down-regulation of Raptor significantly inhibited PIG3-loss-induced increase of HIF-1 $\alpha$ protein level. These results indicated that downregulation of PIG3 may induce HIF-1 $\alpha$ translation in hypoxia via mTOR pathway.

\section{PIG3-silencing promotes the VEGF secretion and migration of renal cancer cells}

Vascular endothelial cell growth factor (VEGF) is one of the major target genes HIF-1 $\alpha[6,21]$. To test whether PIG3 knockdown impairs HIF-1 $\alpha$ biological function, we detected the VEGF secretion in the PIG3silenced CAKI and 769-P cells. As shown in Figure 4A, Silencing PIG3 significantly increased the protein secretion of VEGF under hypoxic conditions. VEGF is the most potent endothelial-specific mitogen and is known to directly participate in angiogenesis and metastasis 
A

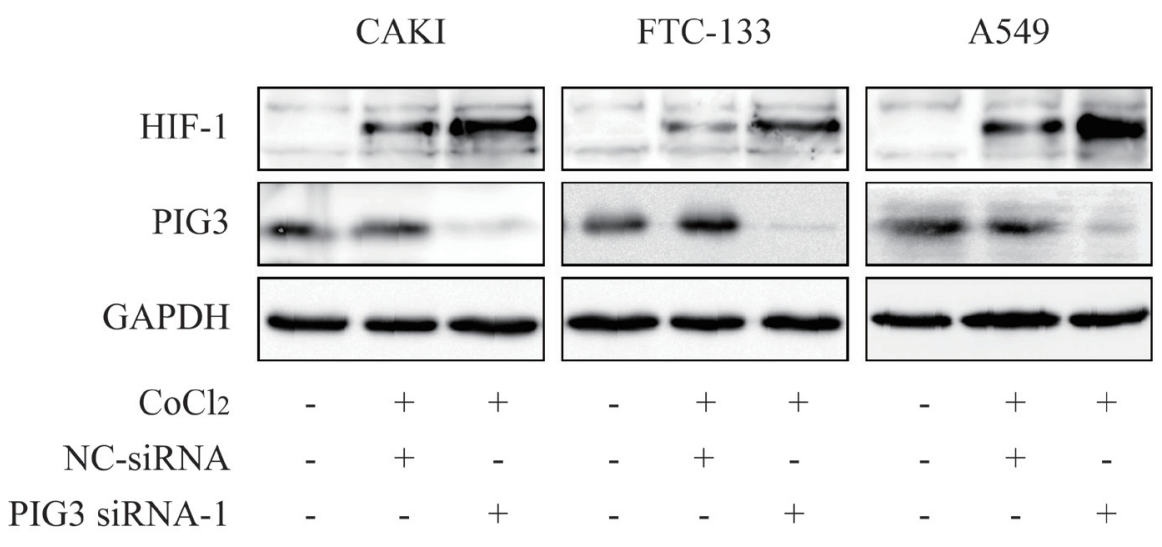

B

C

CAKI

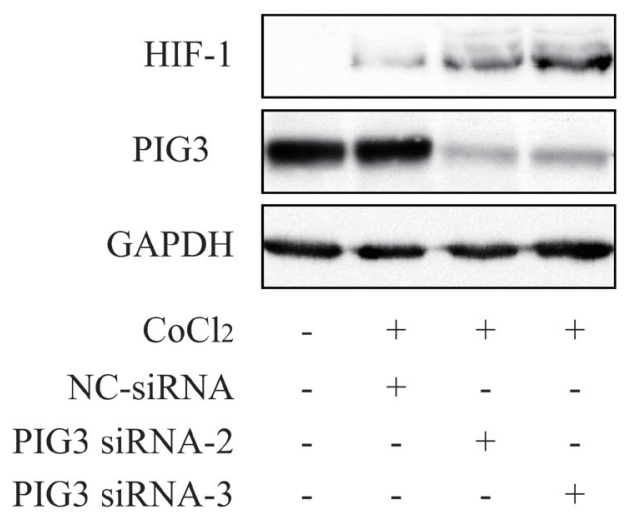

CAKI

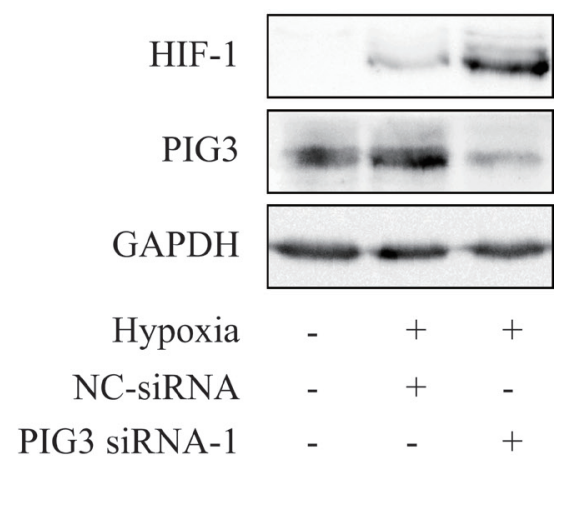

D

\section{CAKI}

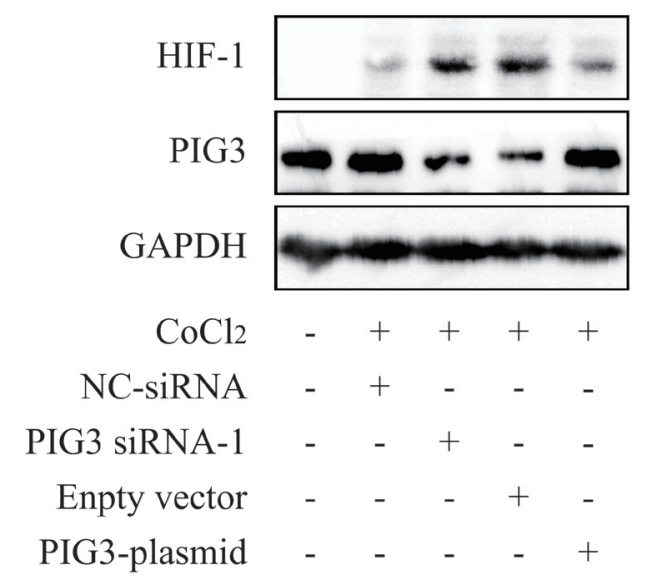

1 gga aat gtt cag get gga gac tat

2 a aat gtt cag get gga gac tat

3 gga aat gtc caa gcc ggg gac tat

$\begin{array}{ccccccccc} & \downarrow & \downarrow & \downarrow & \downarrow & \downarrow & \downarrow & \downarrow & \downarrow \\ 4 & \mathrm{G} & \mathrm{N} & \mathrm{V} & \mathrm{Q} & \mathrm{A} & \mathrm{G} & \mathrm{D} & \mathrm{Y}\end{array}$

1 PIG3 cDNA

2 siRNA PIG3

3 PIG3 plasmid

4 peptide sequence

Figure 1: Knockdown of PIG3 up-regulates HIF-1 $\alpha$. A. PIG3 down-regulation mediated by siRNA-transfection significantly increased HIF-1 $\alpha$ protein level in CAKI, FTC-133 and A549 cells. Cells were transfected with PIG3-siRNA or negative control siRNA for $48 \mathrm{~h}$ before $\mathrm{CoCl}_{2}$-induced hypoxia treatment. B., treatments with both PIG3 siRNA-2 and PIG3 siRNA-3 led to HIF-1 $\alpha$ increase in CAKI cells under $\mathrm{CoCl}_{2}$-induced hypoxia-mimic system for 6 hours. C., HIF-1 $\alpha$ in PIG3 siRNA-1-transfected CAKI cells also increased under hypoxia $\left(1 \% \mathrm{O}_{2}\right)$ for $6 \mathrm{~h}$. D. Complementation with PIG3 blocked HIF-1 $\alpha$ increase induced by PIG3-siRNA. CAKI cells were transfected with the mutant PIG3 plasmid $24 \mathrm{~h}$ after PIG3-siRNA treatment. Protein levels were analyzed by Immunoblotting, GAPDH was employed a loading control. All the experiments above were conducted thrice. 
A

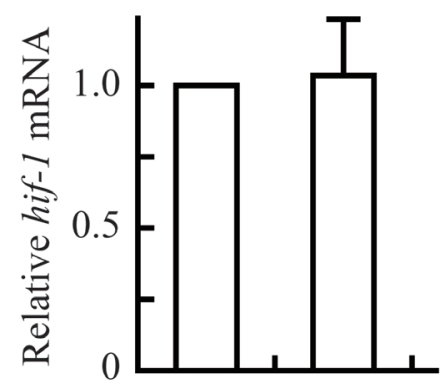

NC-siRNA + -

PIG3 siRNA-1 $\quad-\quad+$

B

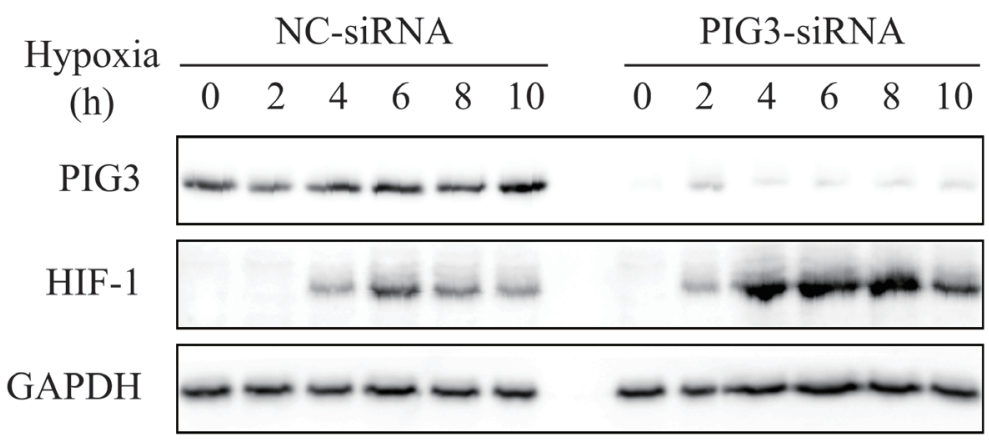

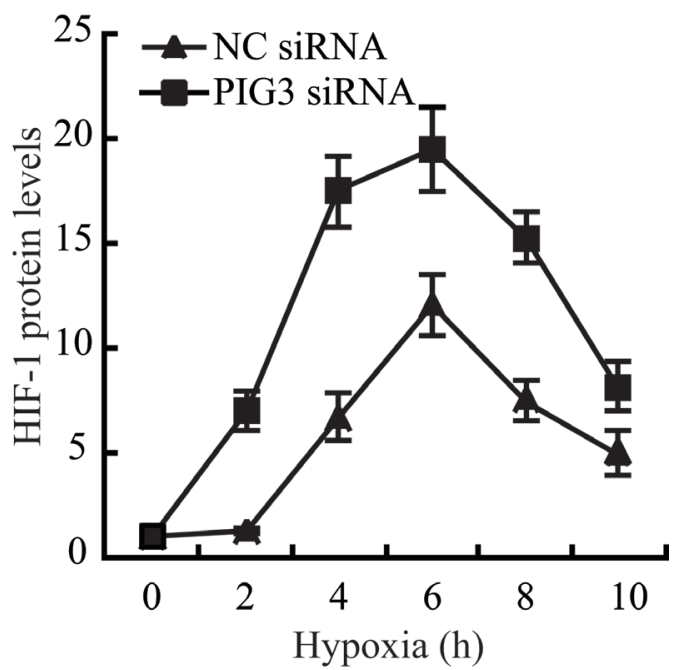

C

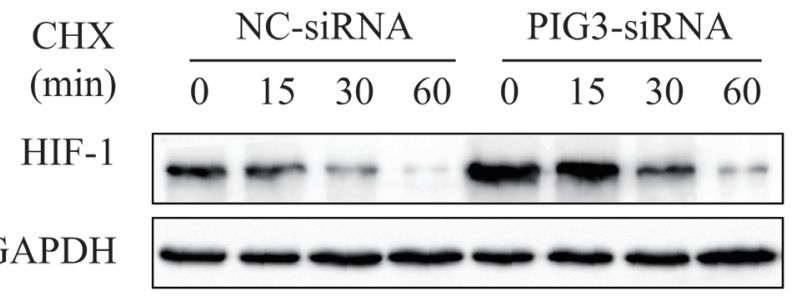

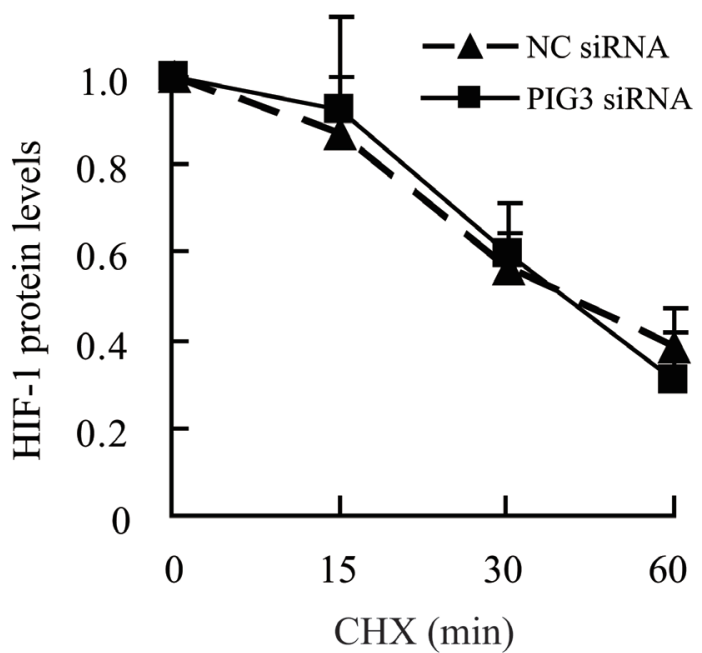

CHX (min)

Figure 2: Knockdown of PIG3 up-regulates prevents HIF-1 $\alpha$ by promoting protein biosynthesis. A., Real-Time PCR analysis showed that PIG3-silencing in CAKI cells did not increase HIF-1 $\alpha$ mRNA level. Data shown are fold-change relative to the HIF$1 \alpha$ levels in cells transfected with negative control siRNA (with normalization relative to GAPDH levels). B., Silencing PIG3 in CAKI cells affected the kinetics of the HIF-1 $\alpha$ protein when the cells were exposed to hypoxic conditions. C., PIG3 silencing did not affect the degradation of HIF-1 $\alpha$ protein under hypoxia. Forty-eight hours after transfection with PIG3-siRNA or negative control siRNA, CAKI cells were pretreated under hypoxia for $4 \mathrm{~h}$ followed by treatment with $100 \mu \mathrm{g} / \mathrm{mL}$ cycloheximide (CHX) to block protein synthesis for the indicated times. The mean values from two experiments are connected by the lines. Protein levels were analyzed by Immunoblotting, GAPDH was employed a loading control. All the experiments above were conducted at least twice. 
[20, 22-25]. To validate the role of PIG3 in metastasisrelated events, we detected the migration of PIG3-silenced CAKI and 769-P cells. Knocking down PIG3 obviously increased the migration activities of CAKI and 769-P cells. However, HIF-1 $\alpha$-knockdown obviously blocked the increase of cell migration induced by PIG3 loss (Figure $4 C$ ), indicating that PIG3-loss increases cell migration in HIF-1a dependent way to some extent.

\section{DISCUSSION}

In the present study, we showed that downregulation of PIG3 by specific siRNA transfection induced the expression of HIF-1 $\alpha$ in CAKI cells. Similar results were replicated in another human cancer FTC-133 and A549 cell lines. PIG3 appeared to involve in regulating HIF-1 $\alpha$. Moreover, we found that knockdown of PIG3 would increase HIF-1 $\alpha$ protein Level via promoting its protein biosynthesis mediated by mTOR pathway. Furthermore, PIG3-silencing increased the secretion of VEGF and promoted the migration of renal cancer cells.

The relationship between p53 and HIF-1 $\alpha$ has been

A

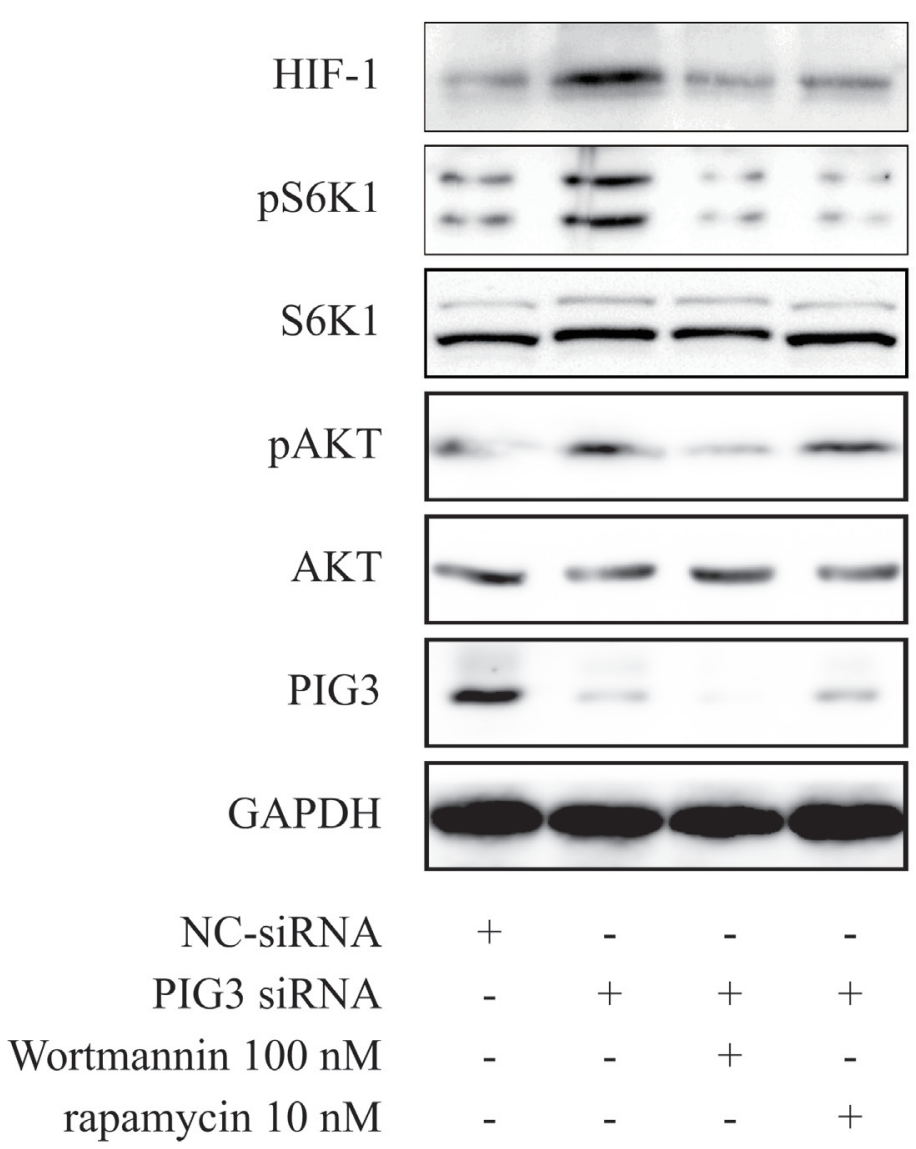

the subject of several studies, which significantly affect cancer progression and compromise treatment outcomes [24]. Kaluzova et al. reported that activated p53 mediates an accelerated degradation of HIF- $1 \alpha$ protein, without affecting significantly HIF-1 $\alpha$ transcription [26]. While Munekazu et al. focused on P53-induced microRNA-107 inhibiting HIF-1 transcription and tumor angiogenesis [27]. It is also reported that p300 is related to the crosstalk between HIF-1 and p53 on the level of trans-activation [28]. It seemed that P53 regulates HIF-1 $\alpha$ at various levels via different pathways [26-34]. As a down-stream target of $\mathrm{p} 53$, the PIG3 is mostly used as a long lived proapoptotic marker [14], and has also been shown to participate in the DNA damage response recently [15]. Although PIG3 activation leads to the ROS generation [16], there is no direct evidences show that PIG3 would regulate HIF-1 $\alpha$. Here we present the evidence to demonstrate that PIG3 functions as a new regulator of HIF-1 $\alpha$. Furthermore, we detailed that loss of PIG3 led to accumulation of HIF-1 $\alpha$ by promoting the HIF-1 $\alpha$ protein biosynthesis via $\mathrm{PI} 3 \mathrm{~K} /$ mTOR pathway.

VEGF is a main target of HIF-1 $\alpha$ and has

\section{B}

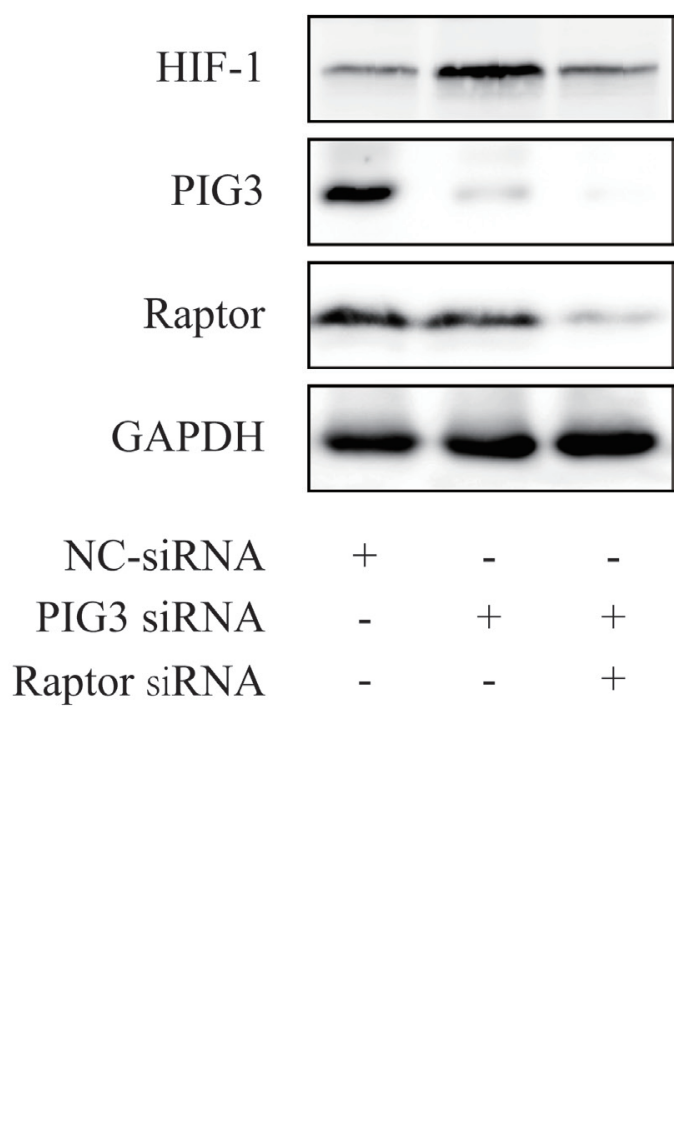

Figure 3: PIG3-silencing promotes the production of HIF-1 $\alpha$ via PI3K/mTOR pathway. A. CAKI cells were transfected with PIG3-siRNA for $24 \mathrm{~h}$, then treatment with rapamycin $10 \mathrm{nM}$ for $24 \mathrm{~h}$ or wortmannin $100 \mathrm{nM}$ for $8 \mathrm{~h}$ before hypoxia treatment. B. CAKI cells were transfected with PIG3-siRNA for $24 \mathrm{~h}$, then treatment with Raptor siRNA for $24 \mathrm{~h}$ before hypoxia treatment. All the experiments above were conducted thrice. 
various effects, including inducing angiogenesis and promoting cell migration $[21,35]$. In this regard we have demonstrated that knockdown of PIG3 promoted VEGF secretion and migration activity of renal cell carcinoma
CAKI and 769-P cells.

In conclusion, our data provide more insights into of PIG3`s role in HIF-1 $\alpha$ regulation, and the regulation network of the cellular HIF-1 $\alpha$. This will help us to
A

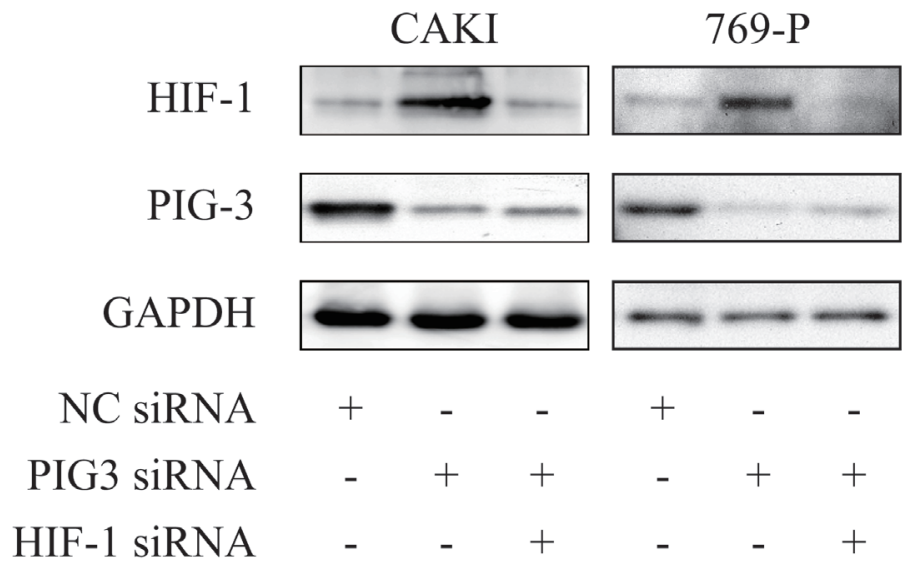

B

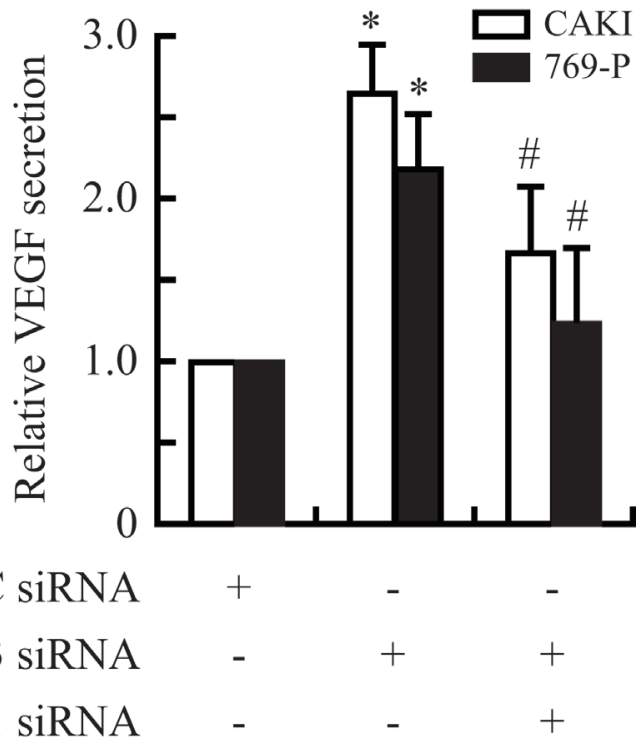

C

\section{CAKI 769-P}
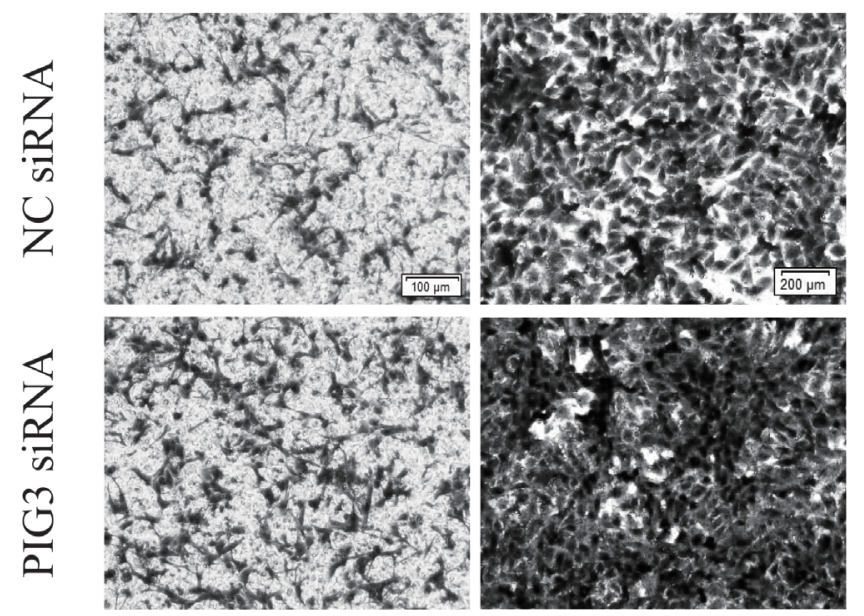

乔

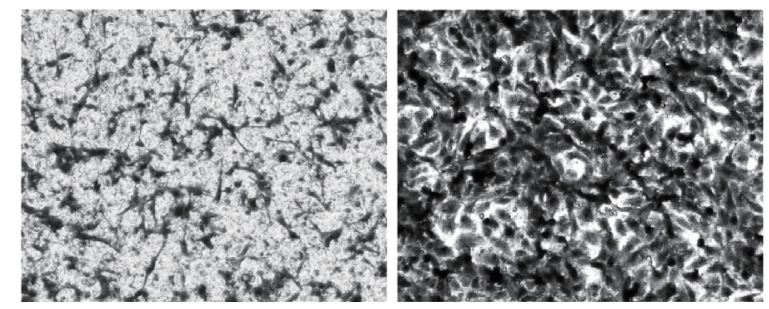

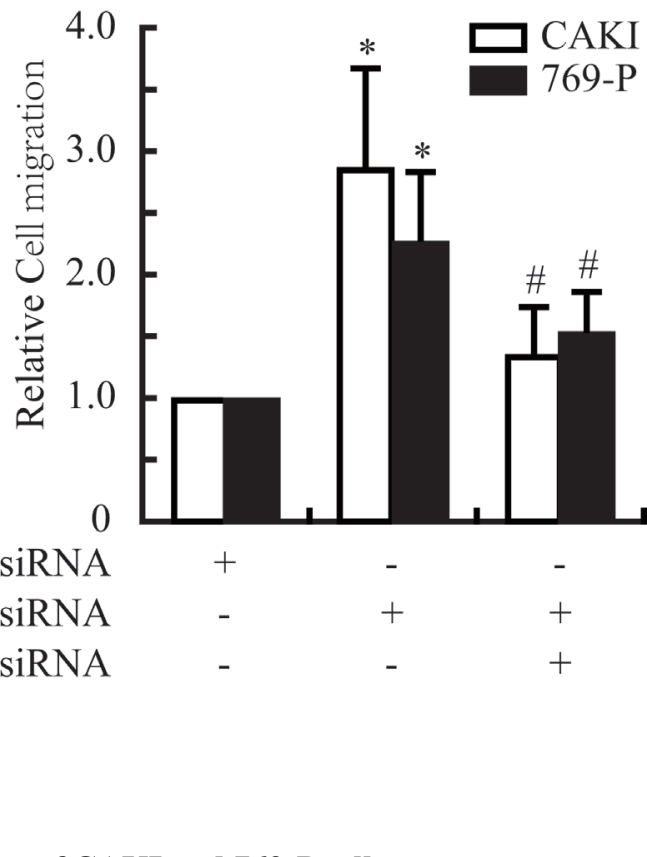

Figure 4: PIG3-silencing promotes the secretion of VEGF and the migration of CAKI and 769-P cells. A., Knocking down PIG3 and/or HIF-1 $\alpha$ by transfecting with siRNA. B., ELISA assays showed that down-regulation of PIG3 led to an increase in the secretion of VEGF via HIF-1 $\alpha$ in CAKI and 769-P cells exposed to hypoxia for $12 \mathrm{~h}$. C., PIG3-silencing promoted CAKI and 769-P cells migration by targeting HIF-1 $\alpha$. All the experiments above were conducted thrice. Columns indicate the mean of three experiments; Bars, S.D. 
understand the tumor progression as well as develop new therapeutic approaches.

\section{MATERIALS AND METHODS}

\section{Cell culture and reagents}

CAKI, FTC133 and A549 cells were obtained from ATCC and maintained in appropriate medium as suggested by ATCC. Cells were incubated in a humidified atmosphere of $95 \%$ air plus $5 \% \mathrm{CO}_{2}$ at $37{ }^{\circ} \mathrm{C} . \mathrm{CoCl}_{2}$ was obtained from Zhiyuan Chemical Reagent Co., Ltd. (Tianjin, China). MG-132 and CHX were obtained from MCE (Shanghai, China). Rapamycin was obtained from LC Laboratories (Woburn, MA, USA). Wortmannin was purchased from Selleckchem.cn (Shanghai, China)

\section{Transfection of siRNA}

Synthetic siRNA were purchased from Shanghai GenePharma Co., Ltd. The siRNA was transfected into cells using siRNA-Mate (Shanghai GenePharma Co., Ltd, Shanghai, China) according to the instructions of the manufacturer, with sequences as follows: pig3 : sense 5-AAAUGUUCAGGCUGGAGACUAdTdT-3. 5-UAGUCUCCAGCCUGAACAUUUdTdT-3; hif-1 $\alpha$ :5-TACGTTGTGAGTGGTATTATT; 5-CUGAUGACCAGCAACUUGATT.

\section{Immunoblotting}

Immunoblotting was conducted with standard procedures [36], using antibodies against PIG3 (Origene, Rockville, MD), HIF-1 $\alpha$ and GAPDH (Santa Cruz Biotechnology, Santa Cruz, CA), p-AKT, AKT, p-S6K1, S6K1 (Cell Signaling Technology, Beverly, MA).

\section{Real-time quantitative PCR}

Total RNA was extracted with Trizol according to the manufacturer's instructions and was transcribed using Prime ScriptTM RT reagent Kit (TaKaRa, Dalian, China). The cDNA template was amplified by realtime PCR using SYBR-PremixExTaqTM Kit (TaKaRa, Dalian, China). The primer sequences were as follows: 5'- TCATCCAAGAAGCCCTAACGTG -3'(forward), 5' - TTTCGCTTTCTCTGAGCATTCTG -3'(reverse) for hif-1 $\alpha, 5$ '-GCACCGTCAAGGCTGAGAAC-3' (forward), 5'-GCCTTCTCCATGGTGGTGAA-3' (reverse) for GAPDH. Thermal cycling was programmed as follows: $95^{\circ} \mathrm{C}$ for $30 \mathrm{sec}$ followed by 40 cycles of $95^{\circ} \mathrm{C}$ for $5 \mathrm{sec}$, $60^{\circ} \mathrm{C}$ for $20 \mathrm{sec}$ and $72^{\circ} \mathrm{C}$ for $15 \mathrm{sec}$, and then $72^{\circ} \mathrm{C}$ for 10 min. Gene expression was assessed by delta $\mathrm{Ct}$ method and mRNA levels of HIF-1 $\alpha$ were normalized to those of GAPDH internal standard.

\section{Transwell assay}

Cell migration was evaluated using an 8-mm pore size Transwell system (Costar, Cambridge, MA, USA). Briefly, Cells were resuspended in serum-free RPIM1640 at a density of $2 \times 10^{5}$ cells $/ \mathrm{mL}$. The top chamber of transwell was loaded with $100 \mu \mathrm{L}$ of cell suspension and the bottom chamber was loaded with $0.6 \mathrm{~mL}$ of RPIM1640 containing $10 \%$ FBS. The total migrated cells to the lower chamber were fixed, stained with $0.1 \%$ crystal violet, and photographed after treatment. Crystal violet stained cells were dissolved with $10 \%$ acetic acid and OD value was measured at $595 \mathrm{~nm}$.

\section{CONFLICTS OF INTEREST}

The authors declare that they have no conflict of interest.

\section{GRANT SUPPORT}

This work was supported by Public Technology Research Projects, Science Technology Department of Zhejiang Province (No. 2016C37111, 2015C37093), National Natural Science Foundation of China (No. 81201530) and Zhejiang Provincial Natural Science Foundation (No. LY15H310001, LY15H310002, LY16H310006).

\section{REFERENCES}

1. Semenza GL. Targeting HIF-1 for cancer therapy. Nature reviews Cancer. 2003; 3:721-732.

2. Semenza GL. Hypoxia-inducible factor 1 (HIF-1) pathway. Science's STKE : signal transduction knowledge environment. 2007; 2007:cm8.

3. Ke Q and Costa M. Hypoxia-inducible factor-1 (HIF-1). Molecular pharmacology. 2006; 70:1469-1480.

4. Semenza GL. Hypoxia, clonal selection, and the role of HIF1 in tumor progression. Critical reviews in biochemistry and molecular biology. 2000; 35:71-103.

5. Semenza GL. HIF-1 and tumor progression: pathophysiology and therapeutics. Trends in molecular medicine. 2002; 8:S62-67.

6. Unwith S, Zhao H, Hennah L and Ma D. The potential role of HIF on tumour progression and dissemination. International journal of cancer Journal international du cancer. 2015; 136:2491-2503.

7. Haase VH. The VHL tumor suppressor: master regulator of HIF. Current pharmaceutical design. 2009; 15:3895-3903. 
8. Park MH, Choi KY, Jung Y and Min do S. Phospholipase D1 protein coordinates dynamic assembly of HIF-1alphaPHD-VHL to regulate HIF-1alpha stability. Oncotarget. 2014; 5:11857-11872. doi: 10.18632/oncotarget.2613.

9. Vanharanta S, Shu W, Brenet F, Hakimi AA, Heguy A, Viale A, Reuter VE, Hsieh JJ, Scandura JM and Massague J. Epigenetic expansion of VHL-HIF signal output drives multiorgan metastasis in renal cancer. Nature medicine. 2013; 19:50-56.

10. Yu B, Miao ZH, Jiang Y, Li MH, Yang N, Li T and Ding J. c-Jun protects hypoxia-inducible factor-1alpha from degradation via its oxygen-dependent degradation domain in a nontranscriptional manner. Cancer research. 2009; 69:7704-7712.

11. Agani F and Jiang BH. Oxygen-independent regulation of HIF-1: novel involvement of PI3K/AKT/mTOR pathway in cancer. Current cancer drug targets. 2013; 13:245-251.

12. Courtnay R, Ngo DC, Malik N, Ververis K, Tortorella SM and Karagiannis TC. Cancer metabolism and the Warburg effect: the role of HIF-1 and PI3K. Molecular biology reports. 2015; 42:841-851.

13. Zhang QL, Cui BR, Li HY, Li P, Hong L, Liu LP, Ding DZ and Cui X. MAPK and PI3K pathways regulate hypoxiainduced atrial natriuretic peptide secretion by controlling HIF-1 alpha expression in beating rabbit atria. Biochemical and biophysical research communications. 2013; 438:507512.

14. Polyak K, Xia Y, Zweier JL, Kinzler KW and Vogelstein B. A model for p53-induced apoptosis. Nature. 1997; 389:300305.

15. Li B, Shang ZF, Yin JJ, Xu QZ, Liu XD, Wang Y, Zhang SM, Guan $\mathrm{H}$ and Zhou PK. PIG3 functions in DNA damage response through regulating DNA-PKcs homeostasis. International journal of biological sciences. 2013; 9:425434.

16. Porte S, Valencia E, Yakovtseva EA, Borras E, Shafqat N, Debreczeny JE, Pike AC, Oppermann U, Farres J, Fita I and Pares X. Three-dimensional structure and enzymatic function of proapoptotic human $\mathrm{p} 53$-inducible quinone oxidoreductase PIG3. The Journal of biological chemistry. 2009; 284:17194-17205.

17. Zhang W, Luo J, Chen F, Yang F, Song W, Zhu A and Guan X. BRCA1 regulates PIG3-mediated apoptosis in a p53-dependent manner. Oncotarget. 2015; 6:7608-7618. doi: 10.18632/oncotarget.3263.

18. Semenza GL. HIF-1: upstream and downstream of cancer metabolism. Current opinion in genetics \& development. 2010; 20:51-56.

19. Demidenko ZN and Blagosklonny MV. The purpose of the HIF-1/PHD feedback loop: to limit mTOR-induced HIF1alpha. Cell cycle. 2011; 10:1557-1562.

20. Leontieva OV, Natarajan V, Demidenko ZN, Burdelya LG, Gudkov AV and Blagosklonny MV. Hypoxia suppresses conversion from proliferative arrest to cellular senescence.
Proceedings of the National Academy of Sciences of the United States of America. 2012; 109:13314-13318.

21. Brugarolas $J$ and Kaelin WG, Jr. Dysregulation of HIF and VEGF is a unifying feature of the familial hamartoma syndromes. Cancer cell. 2004; 6:7-10.

22. Boorjian S. Commentary on "Conditional survival of patients with metastatic renal cell carcinoma treated with VEGF-targeted therapy: A population-based study." Harshman LC, Xie W, Bjarnason GA, Knox JJ, MacKenzie M, Wood L, Srinivas S, Vaishampayan UN, Tan MH, Rha SY, Donskov F, Agarwal N, Kollmannsberger C, North S, Rini BI, Heng DY, Choueiri TK, Stanford Cancer Institute, Stanford University School of Medicine, Stanford, CA: Lancet Oncol 2012;13(9):927-35 (Epub 2012 Aug 8). Urologic oncology. 2013; 31:127-128.

23. Harshman LC, Xie W, Bjarnason GA, Knox JJ, MacKenzie M, Wood L, Srinivas S, Vaishampayan UN, Tan MH, Rha SY, Donskov F, Agarwal N, Kollmannsberger C, North S, Rini BI, Heng DY, et al. Conditional survival of patients with metastatic renal-cell carcinoma treated with VEGFtargeted therapy: a population-based study. The Lancet Oncology. 2012; 13:927-935.

24. Obacz J, Pastorekova S, Vojtesek B and Hrstka R. Crosstalk between HIF and p53 as mediators of molecular responses to physiological and genotoxic stresses. Molecular cancer. 2013; 12:93.

25. Rini BI. VEGF-targeted therapy in metastatic renal cell carcinoma. The oncologist. 2005; 10:191-197.

26. Kaluzova M, Kaluz S, Lerman MI and Stanbridge EJ. DNA damage is a prerequisite for p53-mediated proteasomal degradation of HIF-1alpha in hypoxic cells and downregulation of the hypoxia marker carbonic anhydrase IX. Molecular and cellular biology. 2004; 24:5757-5766.

27. Yamakuchi M, Lotterman CD, Bao C, Hruban RH, Karim B, Mendell JT, Huso D and Lowenstein CJ. P53-induced microRNA-107 inhibits HIF-1 and tumor angiogenesis. Proceedings of the National Academy of Sciences of the United States of America. 2010; 107:6334-6339.

28. Schmid T, Zhou J, Kohl R and Brune B. p300 relieves p53-evoked transcriptional repression of hypoxia-inducible factor-1 (HIF-1). The Biochemical journal. 2004; 380:289295.

29. Vleugel MM, Shvarts D, van der Wall E and van Diest PJ. p300 and p53 levels determine activation of HIF1 downstream targets in invasive breast cancer. Human pathology. 2006; 37:1085-1092.

30. Sano M, Minamino T, Toko H, Miyauchi H, Orimo M, Qin Y, Akazawa H, Tateno K, Kayama Y, Harada M, Shimizu I, Asahara T, Hamada H, Tomita S, Molkentin JD, Zou Y, et al. p53-induced inhibition of Hif-1 causes cardiac dysfunction during pressure overload. Nature. 2007; 446:444-448.

31. Sutton TA, Wilkinson J, Mang HE, Knipe NL, Plotkin Z, Hosein M, Zak K, Wittenborn J and Dagher PC. p53 
regulates renal expression of HIF-1 \{alpha\} and pVHL under physiological conditions and after ischemiareperfusion injury. American journal of physiology Renal physiology. 2008; 295:F1666-1677.

32. Cho IR, Koh SS, Min HJ, Park EH, Ratakorn S, Jhun BH, Jeong SH, Yoo YH, Youn HD, Johnston RN and Chung YH. Down-regulation of HIF-1alpha by oncolytic reovirus infection independently of VHL and p53. Cancer gene therapy. 2010; 17:365-372.

33. Lee SJ, No YR, Dang DT, Dang LH, Yang VW, Shim $\mathrm{H}$ and Yun CC. Regulation of hypoxia-inducible factor 1alpha (HIF-1alpha) by lysophosphatidic acid is dependent on interplay between p53 and Kruppel-like factor 5. The Journal of biological chemistry. 2013; 288:25244-25253.
34. Song H, Yin D and Liu Z. GDF-15 promotes angiogenesis through modulating p53/HIF-1alpha signaling pathway in hypoxic human umbilical vein endothelial cells. Molecular biology reports. 2012; 39:4017-4022.

35. Ahluwalia A and Tarnawski AS. Critical role of hypoxia sensor-HIF-1alpha in VEGF gene activation. Implications for angiogenesis and tissue injury healing. Current medicinal chemistry. 2012; 19:90-97. 